\title{
The Spaces, Politics, and Cultural Economies of Electronic Dance Music
}

\author{
Alistair Fraser*
}

Department of Geography, National University of Ireland Maynooth

\begin{abstract}
This paper examines the spaces, politics, and cultural economies of electronic dance music (EDM). I use geographical literature on EDM to argue that its hedonistic spaces have been forged via cultural economic practices which I conceptualize as constitutive of a process of 'accumulation by cooperation'. In numerous contexts, the people of EDM - the DJs, producers, MCs, artists, promoters, and ravers - have chipped in, worked alongside each other, collaborated, and shared ideas, emotions, and knowledge with a view to producing and re-producing cultural economies and hedonistic spaces shot through by a complex, contradictory politics.
\end{abstract}

\section{Introduction}

During the last 20 years or so and throughout the world, genres of music associated with the generic label 'electronic dance music' (hereafter, EDM) - such as 'house', 'techno', 'trance', 'drum \& bass', and 'dubstep' - have emerged and become relatively popular and influential. These musical varieties are mostly made electronically by combining hardware such as samplers, synthesizers, and drum machines with sophisticated music production software operated on computers. Such technologies make it possible for an artist or producer to make EDM without knowing how to play a musical instrument - an odd idea in the geo-history of music. EDM artists combine technologies and their talents with a general determination to make audiences dance (or, as per some 'downbeat' or 'ambient' genres, to allow audiences to relax or 'chill' before or after they go out to dance) in lateor all-night events in nightclubs and 'raves'. Curiously and with only a few exceptions, EDM is rarely played live by those who make it, in part because performing EDM live is technically difficult, but also because audiences have by-and-large not shown much interest in hearing the music played in this format; rather, EDM is mostly played by 'Disc Jockeys' (hereafter, DJs) who 'mix' together vinyl records, or recordings in MP3 format or on Compact Discs, in raves and nightclubs. Thus, whereas most musical audiences attend concerts in which performers play their music live, EDM audiences attend events in which music by their favourite artists might be played in mixes but rarely by that artist and almost always alongside music from other artists. Audiences therefore hear the music but usually do not see those who made it. Although there are exceptions, with some EDM followers attending events precisely to see their favourite DJ mix, seeing and watching the artist in EDM is not particularly important (Haslam 1997).

The emergence and growth of EDM has been charted by a growing group of academics (e.g. see Collin and Godfrey 1997; Redhead 1993; Redhead et al. 1997; Thornton 1996), with this level of interest culminating in the establishment of Dancecult, a multi-disciplinary academic journal about EDM and its culture. ${ }^{1}$ From the perspective 
of Geography Compass readers, it is worth noting here that geographers have been among those conducting research and writing about EDM (e.g. see Bader and Scharenberg 2010; Brown et al. 2000; Che 2009; Fraser and Ettlinger 2008; Gibson 1999; Halfacree 1996; Halfacree and Kitchin 1996; Ingham et al. 1999; Lange and Burkner 2010; Malbon 1999; Marsh 2006; Pini 2001; Saldanha 2005, 2007). In very general terms, this geographical literature has charted key aspects of EDM's rise, growth, and survival. It has explored some of the spaces and places with which the music has been associated - the clubs, raves, festivals and music studios in which EDM is consumed and produced - and has identified connections between the worlds of EDM and diverse issues of interest in the discipline. Progress has been made. And there are good reasons to expect further contributions, not least from new generations of geographers, many of whom will have grown up listening to and knowing EDM, rather like previous generations knew rock 'n roll.

Against this general backdrop, the following paper examines geographical contributions on EDM with a view to developing an argument about the music's associated geographies. There are two parts to the argument. The first is about the politics of space in EDM. I argue that EDM's existence hinges on the production of what Kath Browne (2007) refers to as 'hedonistic space' in clubs and raves (see also Goulding et al. 2002; Riley et al. 2010). Even if by no means every bit/byte/beat of EDM is made for or enjoyed in clubs or raves, EDM's focus is on the (often highly drug-fuelled) dance floor, that is, on the location in which disparate people can come together to "put their hands up in the air' and 'roll' in spaces of 'freedom, of pleasure, of sonic ecstasy" (Marsh 2006, p. 415). In complex ways, these spaces are highly politicized and it is to some central aspects of these politics that my discussion will turn. One conclusion will be that a raw form of individualism is a key element of the politics of space in EDM. But another, quite different conclusion also emerges when we consider the politics of space in EDM: specifically, EDM has grown thanks in large to practices of collaboration, solidarity, and sharing that are oriented towards producing the hedonistic spaces in which EDM is enjoyed and in which incomes for EDM practitioners can be earned. I therefore use geographical scholarship on these dimensions of EDM to argue that the music has been propelled forwards by 'cultural economic' practices constitutive of what I refer to as 'accumulation by cooperation'.

\section{The Politics of Space in EDM}

Plainly, hedonism is the pursuit of pleasure undertaken by individuals firstly, but always in relation to others and often in tandem with collective action at various scales (e.g. household, community, locality, region, and so on). Realizing hedonistic objectives must therefore always entail the production of space, whether at home, as per a personal quest for sexual pleasure, say, or on the street or in public space. For Browne (2007), such action can yield 'hedonistic spaces', such as those associated with the Pride events she studied in Dublin and Brighton. There, attendees produced hedonistic spaces on the streets during the event and in parties afterwards. These spaces were spatially diverse entities in which "the party, fun, emotion and hedonism" (p. 82) were all central to the highly political dimensions of the Pride event. They were, in short, spaces in which 'parties with politics' would unfold. In my view, EDM clubs and raves in general are also oriented towards generating hedonistic spaces (and as I will discuss, they are also politicized). Although constituted by diverse 'scenes' and locations, EDM events share something in common: they are assemblages of individual and collective actions that materialize hedonistic pursuits; that is, they are the outcomes of the "lust for explosive 
exhilaration" (Simon Reynolds, quoted in Collin and Godfrey 1997, p. 252) that drives EDM music forwards. The club or the rave is a space in which EDM makers and followers - its producers and consumers - can meet up and create the vibe and experience with which EDM tends to be associated; a space in which hedonistic pursuits are manifested in the party, the buzz and the euphoria and in the consumption of numerous commodities, such as styles (and brands) of clothing, the various technologies that seek to realize the hedonistic objective, such as lighting, smoke machines, and of course sound equipment, and of course alcohol and other illicit substances.

In this regard, and without question, a crucial point to note is that use of a range of substances goes a long way towards the construction of EDM's hedonistic spaces. Particularly important in EDM's development has been MDMA (3,4-Methylenedioxymethamphetamine), popularly known as 'ecstasy'. As Malbon (1999) and Pini (2001) noted in some of the earliest geographical research on the spaces of EDM, ecstasy has played a major role in defining how the focal points of EDM should be experienced (see also Brown 1997; Chatterton and Hollands 2003; Saldanha 2007). For example, for some of the women in Pini's (2001) research, raves were uniquely inviting because ecstasy use altered the sexual politics of 'traditional' forms of clubbing: some women felt more at ease because men were more interested in dancing and enjoying the music than in 'picking up' a partner, hence women were less likely to be pestered. More generally, ecstasy use encouraged music producers to make euphoric, uplifting music, a trait still found throughout EDM genres today. But as drug use researchers have also noted, the raves and clubs in which EDM is played are not just about ecstasy use. For example, drugs such as ketamine have become part of the 'pleasure nexus' (Moore and Measham 2008) in the last decade or so in Britain; and alcohol plays a major role in many EDM experiences, not only in clubs but also before and after EDM events. The point, therefore, is not that EDM is about ecstasy but that it is closely associated with use of a range of substances that seek to amplify the hedonistic experience of enjoying the music in specific types of spaces.

I argue that recognizing the importance of hedonistic space in EDM is important because it helps to explain why, with few exceptions, it is hard to find much of a political message in EDM. Even if there is a clear element of resistance and subversion associated with some EDM genres and practices (e.g. see Fraser and Ettlinger 2008; Gibson 1999; Nayak 2006), and some of its followers have been associated with some serious political statements about rights and visions of the city (e.g. see Che 2009; Marsh 2006), it seems hard to avoid the conclusion that partying, fun, pleasure, dancing, and the vibe outweigh the explicit political orientation of EDM. The political dimensions of EDM overwhelmingly tend to be secondary to the more pressing and more enduring objectives of partying, raving, and clubbing. However, this is not to suggest that EDM's hedonistic spaces are devoid of politics. Rather, a point to dwell upon is the politics conjured up by the personal and collective hedonistic pursuits that underpin EDM. Given that the drive for creating personal hedonistic experiences occurs alongside other people and their needs and wants, I argue there is an inevitable politics of space within EDM. Let me highlight a few issues here that call into question the too-often taken-for-granted notion that EDM is about Peace, Love, and Unity (PLUR) (on this, see Measham and Hadfield 2009).

The first is that EDM's hedonistic spaces are by no means inclusive, open, or progressive. In British Drum \& Bass, for example, some DJs tend to stick to visceral, 'harder' styles that appeal to only some members of the audience, despite pressure from promoters to alter their style and broader their appeal. More broadly, misogynist and sexist attitudes pervade D\&B, which has had knock-on effects on the number of women attending 
events (Fraser and Ettlinger 2008). A second is to note the centrality of various forms of elitism in EDM (e.g. see Measham and Hadfield 2009; Talbot and Böse 2007; also Collin and Godfrey 1997), with some clubs and events seeking a wealthy clientele by using security personnel to turn away undesirables, such as young working class men. For such young men in northeast England, elitism and exclusion compels them to construct their own "hidden arenas of pleasure in the night-time economy" (Nayak 2006, p. 821; also Chatterton and Hollands 2003, pp. 202-231). A third issue is the racist attitude of some 'Goa freaks' towards Indian tourists who they fail to sufficiently welcome on the early morning beach, leading to "sensuous configurations" (Saldanha 2005, p. 710) of race, class, sexuality, ethnicity, and region within EDM's hedonistic spaces that are generative of exclusion as well as inclusion, closure as well as openness (see also Saldanha 2007).

Finally, an even more general point to make about EDM is that its hedonistic spaces are reflections (and in some respects, possibly even celebrations) of neoliberal sensibilities about individual rights and consumption practices (see McDowell 2004; Mitchell 2003). According to neoliberal thinking, individuals should pursue their personal goals within atomized societies - indeed, arguably, 'there is no such thing as society' in these neoliberal times - and only minimum interventions from governments or states should interfere with the freedom to produce, accumulate, or indeed consume (for an excellent overview of neoliberalism, see Harvey 2005). It is hard to avoid the conclusion that just such an element of raw individualism pervades EDM. There is, for example, a degree to which an individual's pursuit of enjoyment is about finding a space to dance, to 'mash up da place'; an ethos which maps neatly onto the spirit of neoliberalism, which is about promoting (certain, mainly market-oriented) personal freedoms and individual fulfilment (Mitchell 2003). There is also in EDM a strong entrepreneurial spirit, which has led many practitioners to start their own businesses and hence become neoliberal champions (or, if not champions, then at least real world embodiments) of the merits of competition and wealth accumulation. In these senses, the spaces of EDM reflect atomized societies generally, societies in which the individual pursuit of pleasure is a necessary element in valorizing cultural products (Zukin 1990), such as EDM.

These examples of exclusion, elitism, racism, and individualism call attention to the awkward place of politics within EDM: on the one hand, EDM rarely contains much of a political message, whilst on the other hand the spaces on which it hinges are riddled with political tensions and divisions. But yet, while acknowledging the presence of some of the uglier aspects of EDM's politics is unavoidable, I also want to suggest that a different picture of its politics emerges when we consider some of the practices that its followers use to put together those hedonistic spaces. Indeed, in addition to recognizing individualism and competitiveness in EDM, I argue in the next section that we must also acknowledge the significance of ideas, sensibilities, and mentalities that depart quite considerably from those that neoliberalism promotes. Let me now turn to this part of the argument.

\section{Cultural Economic Practices and Accumulation in EDM}

Since David Harvey (2003) introduced the idea of 'accumulation by dispossession' in his efforts to grasp and explain the significance and nature of contemporary capitalism, especially its neoliberal form, geographers have dreamt up numerous other 'accumulation by' concepts. For example, Kitchin et al. (forthcoming) have coined the phrase 'accumulation by repossession' in reference to Ireland's property bubble and crash; and David Nally (2011) has used the term 'accumulation by molecularisation' to come to terms with the 
effort on the part of agri-TNCs to capture value in the food chain. ${ }^{2}$ Underpinning these 'accumulation by' ideas is a Marxist ontology of capital. It is raw, pure capital: a malignant social force chasing after profits at all costs; a force compelling actors to dispossess smallscale farmers of their land, restore profitability of 'faulty institutions' using public monies, or enable molecular-scale experimentation driven by the promise of future patents and profits. In short, geographers' 'accumulation by' concepts have in mind classical modes of capitalist accumulation, albeit framed by particular circumstances. As is the case in other segments of the music industry and cultural industries more broadly, capitalist accumulation is certainly a major part of EDM. Small independent record companies make profits, re-invest and try to grow whilst continuing to make profits (see Hesmondhalgh 1998); event promoters engage in similar processes whilst producing raves or festivals or running club nights; and some DJs and producers get rich by commanding enormous performance fees or selling recordings. There is money to be made and there are jobs to be found in EDM (e.g. see Fraser and Ettlinger 2008; or McGregor and Gibson 2009; and on the parallel case of hip-hop's economy, see Basu and Werbner 2001). There is a capitalist economy of EDM and so it is correct to consider how specifically capitalist accumulation occurs in EDM. But yet, it is also hard to avoid the conclusion that another type of accumulation seems to matter in the world of EDM. Returning to the idea that EDM has a hedonistic element, a sensibility towards the party and vibes, I argue it makes sense to dwell upon what, in addition to money, has been accumulated in the 20 or so years of EDM.

In this regard, a particularly striking recent development in the world of EDM is the discussion of \#junglememories on the social networking web site, Twitter. ${ }^{3}$ This hashtag resulted in an extensive, geographically diverse and often reflexive series of statements among makers and followers of jungle / drum \& bass music. Lots came up, of course, but one central feature was the extent to which those who make and promote D\&B have 'accumulated', but not just in the strictly Marxist sense. Rather, many reflected on how they had gained positive memories, experiences, knowledge, skills, and acquaintances. Some emphasized how their experience was about, "Building everything outta nothing, and I mean nothing “(DJ Hype / @DJHype_Playaz, Dec 11 2011), whilst also "Sharing knowledge and opening doors for others as i [sic] was always eager to help everyone whether they liked it or not" (DJ Hype / @DJHype_ Playaz, Dec 11 2011). Or, as MC 2Shy remembered, how jungle / drum \& bass was, "A scene that broke down all barriers regarding races, colours and creeds purely for the love of music"(@2ShyMC, Dec 9 2011). What I argue we can detect in these sorts of comments is a broader-than-capitalist form of accumulation that has occurred in EDM genres such as D\&B: not just profits and wealth, which has been the case for some of the more prolific actors, but also the far-less-material yet still highly valuable individual and collective experience of making a world, a space for themselves and their followers. In EDM, then, as is the case more generally among economic practitioners, there is more to accumulation than profits alone.

It is useful to note at this juncture that some geographical scholarship has made just such a point about the logics of EDM. Of particular importance are those contributions dealing with the 'cultural economies' of EDM (e.g. Bader and Scharenberg 2010; Fraser and Ettlinger 2008; McGregor and Gibson 2009). This line of work takes seriously the increasing prominence of cultural products in contemporary capitalist society generally (e.g. see Zukin 1990, 1995; also Scott 2001), an understanding of which entails recognizing that economic activity is always influenced by tastes, emotions, sensibilities, pleasures and seductions. It follows from this observation that the economy is a "culturally infused 
entity" (Amin 2009, p. 129); and that, despite the separations we might tend to imagine existing between them, "realms of life [such as the economic and the cultural] are mutually embedded" (Ettlinger 2003, p, 149). As Gibson (2003, p. 211) notes, therefore, "Activities assumed to be 'creative' or 'cultural' have economic dimensions (not least in the conditions of work and remuneration), but so too are the 'economic' constituents of the cultural industries - firms, labour, spaces of production and performance - also sites that are culturally produced, about which discourses are made, enacted and contested" (Gibson 2003, p. 211). I argue that a major contribution of geographical scholarship on EDM is the attention it has given to these cultural economies, ranging from work on the overall industry of British drum \& bass music (Fraser and Ettlinger 2008), to the economic and cultural struggles faced by DJs in Australia (McGregor and Gibson 2009) and the cultural economy of Berlin's Techno music scene (Bader and Scharenberg 2010). These contributions have deepened our understanding of EDM and its producers and followers. But I want to suggest that they also draw attention to a specific logic of cultural economic practice in EDM. Specifically, in the following discussion, I depart from strictly Marxist imaginaries of capital underpinning other 'accumulation by' concepts in geography and instead use geographical scholarship on EDM to argue that it has developed thanks to a process of 'accumulation by cooperation'. Notwithstanding the ruthlessness the masculinist entrepreneurial spirit celebrated in TV shows such as The Apprentice - that does exist in EDM (just like any other economy, there are conflicts and disagreements, swindlers, thieves and gangsters), I use the geographical literature on EDM to emphasize the importance of relations of solidarity, reciprocity, generosity, caring, and empathy. I suggest these cooperative practices stem from the contexts in which actors in EDM operate and that they enable accumulation of profit and experience, economic and cultural gains. My approach is to select insights from the geographical literature on EDM that highlight some of the ways that accumulation by cooperation occurs. I organize these points heuristically by locating them in what Leyshon (2001) theorizes as the four networks of the musical economy: that is, networks of creativity, reproduction, distribution, and consumption. Using these examples from the literature, I therefore call attention to some of the ways we can glimpse, hear, or feel how cooperation pervades the effort to forge EDM's hedonistic spaces.

\section{NETWORKS OF CREATIVITY}

Especially in British drum \& bass music's first decade (approximately 1995-2005), music producers and DJs collaborated in a peer-review quality assurance mechanism they labelled 'dub plate culture', in which music producers had their latest tracks 'pressed' onto relatively inexpensive acetate dub plates and tested by DJs inside events before releasing the track for general sale (see Fraser and Ettlinger 2008). Dub plate culture was intensely collaborative and ensured a rapid flow of new music, which helped keep D\&B fresh, exciting, and experimental, and which sought to produce buzzing, running, bubbling dance floors (see also Belle-Fortune 1999; also on the D\&B dance floor see Christodoulou 2011). This spirit of experimentation continues today, albeit without relying so much on actual dub plates. The collaborative spirit persists, too, as can be felt in the following quote from a D\&B MC upon signing out of a radio show: "Hold tight all the DJs, all the MCs, all the producers, promoters, everybody involved in our scene in England abroad, everywhere, making it strong. Remember it's not about competing, it's about linking, making it bigger" (MC Eksman live on http://www.koollondon.com with DJ Logan-D and MC Herbzie, 17th July 2011). Of course, that ethos of 'linking, making it 
bigger' is not the only one in $\mathrm{D} \& \mathrm{~B}$, but it does emphasize that a form of accumulation beyond the strict Marxist understanding does exist and that this other accumulation is made possible thanks in part to cooperative practices (on DJ collectives designed to promote events and 'offset risk' in Dunedin, Australia, see McGregor and Gibson 2009, pp. 284-285).

\section{NETWORKS OF REPRODUCTION}

Here, too, there is ample evidence of cooperative practices in EDM. For example, like the development of EDM in other places - e.g. the warehouse parties in ManchesterBlackburn (Brown et al. 2000; also Halfacree and Kitchin 1996), Sydney (Gibson 1999), and Toronto (Marsh 2006) - Berlin's Techno music scene emerged and survived thanks to bottom-up cooperation among squatters and those running events in post-industrial vacant spaces (Bader and Scharenberg 2010). The appropriation and use of these spaces and the music that was made to be played in them helped to make Berlin one of the world's most important sites for EDM. Subaltern, grassroots, underground cooperation mattered. But the story of Berlin's Techno music is also about other forms of cooperation: specifically, the city's small independent music companies have found ways to grow, in turn giving Berlin prominence in the "global cultural economy precisely because of its strong subcultural basis" (Bader and Scharenberg 2010, p. 88), by entering into partnership arrangements with global media corporations. A process of accumulation by cooperation among actors within and beyond the scene has therefore enabled Techno to survive within Berlin and reach a global audience.

\section{NETWORKS OF DISTRIBUTION}

For Leyshon (2001), these networks are dominated by capitalist recording companies. In EDM, too, recording companies are important, as Bader and Scharenberg note. But distribution in EDM is not just about moving records, CDs or MP3s; rather, EDM is also about the distribution of people, of ideas and sensibilities connecting disparate individuals and groups from far afield and often coalescing in particular places. Occurrences in 'virtual' spaces on the Internet are important here because these sites can be, "used as a support mechanism for a series of subversive activities in real physical space" (Gibson 1999, p. 30), such as advertising and promoting events but also connecting together actors within distant scenes into a broader geography of knowledge, collaboration and action (see also Chatterton and Hollands 2003). In terms of action in networks of distribution, Goa is a standout example. As Saldanha (2005, 2007) highlights, Anjuna in Goa is a countercultural Mecca for other trance and psy-trance scenes, "all over Western Europe, but also in California, Israel, Japan, Australia, Slovenia, South Africa, Brazil and Russia” (2005, p. 708). Physically getting to Goa is central to the scene's survival. But within Goa, Saldanha notes how local actions instigated by, "gangs of local boys, restaurant owners, foreign deejays and drug dealers" (p. 709) distribute people around Goa, making events possible, and producing Goa's hedonistic spaces. We therefore see here how accumulation of trance music experiences and vibes combines with accumulation of money and wealth by "local families [who] have directly or indirectly lived off party tourism for decades now" (p. 708) and some of the successful DJs, many of whom have toured beyond Goa based on the cultural capital they accumulated there. 
EDM relies on consumption in record shops, online and in its hedonistic spaces in clubs and raves. Geographical scholarship on EDM has helped illuminate some critical cooperative practices that constitute these spaces. Malbon $(1999$, p. 26), for example, has drawn attention to, "an ethos of sharing something extraordinary [which] evolves between those within the dancing crowd" in London's clubs. The heat, the energy, the drugs perhaps, and then the throbbing, rumbling, or rolling music combine to foster an alternative experience; a sort of space, however fleeting and partial, that departs from those experienced in daily diurnal life within capitalist society and tend (and indeed are intended) to differ from what is available in mainstream night-time venues. But it is not just in the club that sharing occurs. Rather, Malbon notes how, "the post-clubbing period is about reflection, recovery, sharing their experiences and engaging in quite different forms of interaction to those of clubbing" (p. 171). In networks of consumption, then, sharing, solidarity and cooperation help to create EDM's hedonistic spaces. These 'practices of sociality' Malbon (1999) draw on alternative mentalities about reciprocity that have, at times, yielded political movements intended to protect the right to construct such spaces. In Toronto, Canada, for example, EDM followers organized a movement against state-led action to restrict their rights to party (see Marsh 2006 also, on Britain's Criminal Justice and Public Order Act 1994, see Brown 1997).

In summary, then, I have argued that EDM hinges on the production of hedonistic spaces; it exists and survives because there will be a dance floor, a chill-out zone, or (smelly, hot, heaving) liminal spaces between clubber and DJ or clubber and others. It is made up of numerous, often overlapping cultural economies that enable many people to make a handsome living out of making or playing EDM. But making a living is not the be-all-and-end-all: there is accumulation, profits are made, growth occurs, some economic players become dominant and might even use their market power in much the same way as we would expect capitalist firms to act, but accumulation of profits, or money, or an income is not all that matters in EDM. There are other accumulations: actors in the cultural economies of EDM also care about and are oriented towards accumulating experiences, memories, skills, knowledge, and respect. In short, EDM is about a broader notion of accumulation and, crucially, this form relies extensively on cooperative relations that depart significantly from normalized practices in the mainstream capitalist economy and labour market. As I have demonstrated, geographers have (perhaps inadvertently) called attention to numerous ways that such forms of cooperation matter. In the process of interrogating the spatialities of EDM, they have illuminated practices and ideas, relations and actions that generate the spaces of EDM and enable accumulation by cooperation to occur.

\section{Conclusion}

I have used geographical contributions to the literature on EDM to shed light on some of its associated geographies. These geographies are diverse, mobile, fleeting, and complex: there are hotspots of creative activity (cities such as London, Detroit, or Berlin), places that stand out on the map of EDM (Goa, Ibiza, or Manchester), and, crucially, within all of these locations there are particular types of spaces in clubs and raves that need to be forged for EDM to survive and grow. I have paid particular attention to the politics of space in EDM and then the importance of cultural economic practices in the making of those spaces. The spaces of EDM are highly politicized and in complex ways; 
there is a politics to EDM that can be hard to pin down. I have tried to explore some of the most prominent elements as discussed in the geographical literature, not the least of which has been the tension between individualistic and collective sensibilities and mentalities among EDM practitioners and followers. A task for future geographical scholarship on EDM might be to shed more light on how this tension is negotiated in different sorts of contexts.

Another task for future work, I would like to suggest, is to explore EDM genres that have been ignored hitherto, not least the 'sunrise' genres such as dubstep. Further, the landscape of EDM charted by geographers could be expanded. For example, it would be exciting to see geographical scholarship on some of the new sites in EDM's map, such as Popovka in Ukraine, or on places in Latin America or Asia. Another much-needed exercise is to quantify the size, scale, and reach of EDM. As Figure 1 shows, many ravers are

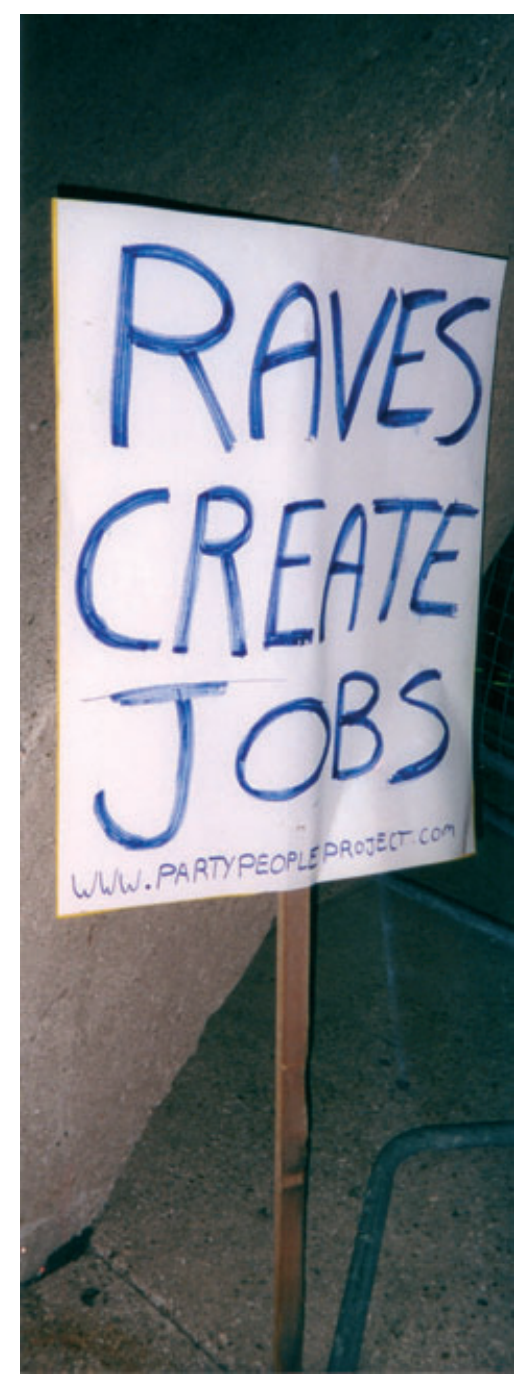

Fig.1. A placard photographed by the author at the 'idance' protest held at Nathan Phillips' Square, Toronto on 1 August 2000. 
aware of their economic potential, but survey data is needed for others to understand what EDM has meant and continues to mean within the broader economy. A related and noteworthy source of data is the cadre of 'back office staff' which performs essential tasks in, but is mostly ignored in studies of, EDM. There are, for example, numerous booking agents, graphic designers, and $A \& R$ staff. These are the workers that help make EDM 'creative' and 'cultural'.

A final under-used resource is the archive of EDM 'texts'. Many EDM genres are short on lyrical content, but there are prominent lyricists in genres such as drum \& bass, grime and dubstep, not least the MCs who perform live and on recordings. Like hip-hop or ragga artists, these MCs speak about their lives, their worlds, and the 'scenes' in which they operate. Yet, unlike hip-hop lyrics and lyricists, who have received scholarly attention, (e.g. see Forman 2002), there has not been any research on EDM texts. Just what do lyricists say? As Yarwood and Charlton (2009) have demonstrated with respect to folk musicians in Britain's West Country, analyses of song lyrics can yield insights about the contexts musicians reflect and produce. There is scope for a similar type of research regarding EDM.

\section{Acknowledgements}

I would like to thank Nancy Ettlinger for sharing her thoughts with me on this topic in general and for helping me improve this particular paper. For their critical but generous comments and suggestions, I also thank the editor, Ian Cook, and the anonymous reviewers.

\section{Short Biography}

Alistair Fraser's research cuts across political, economic, and cultural geography. One line of work focuses on agrarian change, development, and globalization. Examples of his work in this area have been published in Tijdschrift voor Economische en Sociale Geografie, Social and Cultural Geography, and Political Geography. Another area of empirical interest is EDM, which stems from almost 20 years of engagement with the music, both in terms of his lived experience and intellectual development. One outcome of his explorations in this regard is a paper in Geoforum on the dynamic cultural economy of British Drum \& Bass which he co-authored with Nancy Ettlinger. His current work on EDM entails theoretical and empirical research on the cultural and economic significance of lyrics in EDM. He has been a Visiting Lecturer at Rhodes University, South Africa and has been a post-doctoral researcher at University College Dublin, Ireland. He currently lectures in the Department of Geography at the National University of Ireland Maynooth. He holds a $\mathrm{MA}$ and $\mathrm{PhD}$ in Geography from The Ohio State University.

\footnotetext{
Notes

* Correspondence address: Alistair Fraser, Rhetoric House, Maynooth, Co. Kildare, Ireland. E-mail: alistair. fraser@nuim.ie

1 Worth also mentioning here is Dancecult's bibliography of work on EDM. As of February 2012 this includes 320 sources. See: http://www.dancecult.net/bibliography.php

2 With reference to Arctic climate change, for example, Leigh Johnson (2010) also coins the term 'accumulation by degradation'.
} 
3 See the full range of tweets here: http://junglememoriesarchive.tumblr.com/. And there have been other '\#memories' discussions, such as \#garagememories, \#hardcorememories, etc.

4 As a parallel, consider here Basu and Werbner's (2001) study of US hip-hop, which revealed the extent to which practitioners forged a cultural economy that offered a wide range of employment opportunities in a de-industrializing economy. The case of hip-hop indicates that, whilst DJs, producers, or owners of record companies might earn the largest incomes, there are plenty of others who find work and make some sort of a living. How do those actors survive and what do they contribute to EDM? EDM's flexible, small firms pursuing niche markets are typical of the post-Fordist, post-industrial era of 'flexible accumulation' (Harvey 1988); but are their workplaces distinctive and, if so, how?

\section{References}

Amin, A. (2009) Cultural economy. In: Gregory, G., Johnston, R. J., Pratt, G., Watts, M. J. and Whatmore, S. (eds) The dictionary of human geography (5th ed.). Oxford, UK: Blackwell, pp. 128-129.

Bader, I. and Scharenberg, A. (2010). The sound of Berlin: subculture and the global music industry. International Journal of Urban and Regional Research 34 (1), 76-91.

Basu, D. and Werbner, P. (2001). Bootstrap capitalism and the culture industries: a critique of invidious comparisons in the study of ethnic entrepreneurship. Ethnic and Racial Studies 24 (2), 236-262.

Brown, A. (1997). Let's all have a disco? Football, popular music and democratization. In: Redhead, S., Wynne, D. and O'Connor, J. (eds) The clubcultures reader: readings in popular cultural studies. Malden, MA: Blackwell, pp. 6183.

Brown, A., O’Connor, J. and Cohen, S. (2000). Local music policies within a global music industry: cultural quarters in Manchester and Sheffield. Geoforum 31 (4), pp. 437-451.

Browne, K. (2007). A party with politics? (Re)making LGBTQ Pride spaces in Dublin and Brighton. Social \& Cultural Geography 8 (1), pp. 63-87.

Chatterton, P. and Hollands, R. (2003). Urban nightscapes: youth cultures, pleasure spaces and corporate power. London: Routlege.

Che, D. (2009). Techno: Music and entrepreneurship in post-Fordist Detroit. In: Johannson, O. and Bell, T. L. (ed.) Sound, society and the geography of popular music. Farnham (UK): Ashgate Publishing, pp. 261-280.

Christodoulou, C. (2011). Rumble in the jungle: city, place and uncanny bass. Dancecult: Journal of Electronic Dance Music Culture 3 (1), pp. 44-63.

Collin, M. and Godfrey, J. (1997). Altered state: the story of ecstasy culture and acid house. London: Serpent's Tail.

Ettlinger, N. (2003). Cultural economic geography and a relational and microspace approach to trusts, rationalities, networks, and change in collaborative workplaces. Journal of Economic Geography 3, pp. 145-171.

Forman, M. (2002). The 'hood comes first: race, space, and place in rap and hip-hop. Middletown, Conn.: Wesleyan University Press.

Fraser, A. and Ettlinger, N. (2008). Fragile empowerment: the dynamic cultural economy of British drum and bass music. Geoforum 39 (5), pp. 1647-1656.

Gibson, C. (1999). Subversive sites: rave culture, spatial politics and the internet in Sydney, Australia. Area 31 (1), pp. 19-33.

Gibson, C. (2003). Cultures at work: why 'culture' matters in research on the 'cultural' industries. Social $\mathcal{E}$ Cultural Geography 4 (2), pp. 201-215.

Goulding, C., Shankar, A. and Elliott, R. (2002). Working weeks, rave weekends: identity fragmentation and the emergence of new communities. Consumption Markets \& Culture 5 (2), pp. 261-284.

Halfacree, K. H. (1996). Out of place in the country: travellers and the "rural idyll". Antipode 28 (1), pp. 42-72.

Halfacree, K. H. and Kitchin, R. M. (1996). 'Madchester rave on': placing the fragments of popular music. Area 28 (1), pp. 47-55.

Harvey, D. (1988). The geographical and geopolitical consequences of the transition from Fordist to flexible accumulation. In: Sternlieb, G. and Hughes, J. W. (eds) America's new market geography. New Brunswick, NJ: Rutgers Center for Urban Policy Research, pp. 101-134.

Harvey, D. (2003). The new imperialism. Oxford: Oxford University Press.

Harvey, D. (2005). A brief history of neoliberalism. Oxford: Oxford University Press.

Haslam, D. (1997). DJ culture. In: Redhead, S., Wynne, D. and O'Connor, J. (eds) The clubcultures reader: readings in popular cultural studies. Oxford: Blackwell, pp. 150-161.

Hesmondhalgh, D. (1998). The British dance music industry: a case study of independent cultural production. British Journal of Sociology 49, pp. 234-251.

Ingham, J., Purvis, M. and Clarke, D. B. (1999). Hearing places, making spaces: sonorous geographics, ephemeral rhythms, and the Blackburn warehouse parties. Environment and Planning D-Society and Space 17 (3), pp. $283-305$.

Johnson, L. (2010). The fearful symmetry of Arctic climate change: accumulation by degradation. Environment and Planning D: Society and Space 28 (5), pp. 828-847. 
Kitchin, R., et al. (forthcoming). Placing neoliberalism: the rise and fall of Ireland's Celtic Tiger. Environment and Planning $A$.

Lange, B. and Burkner, H. J. (2010). Creation of value in creative industries. The case of electronic club music. Zeitschrift fur wirtschaftsgeographie 54 (1), pp. 46-68.

Leyshon, A. (2001). Time-space (and digital) compression: software formats, musical networks, and the reorganisation of the music industry. Environment \& Planning A 33 (1), pp. 49-77.

Malbon, B. (1999). Clubbing: dancing ecstasy and vitality. London: Routledge.

Marsh, C. (2006). 'Understand us before you end us': regulation, governmentality, and the confessional practices of raving bodies. Popular Music 25 (3), pp. 415-430.

McDowell, L. (2004). Work, workfare, work/life balance and an ethic of care. Progress in Human Geography 28 (2), pp. 145-163.

McGregor, A. and Gibson, C (2009). Musical work in a university town: the shifting spaces and practices of DJs in Dunedin. Asia Pacific Viewpoint 50 (3), pp. 277-288.

Measham, F and Hadfield, P (2009). Everything starts with an 'E': exclusion, ethnicity and elite formation in contemporary English clubland. Adicciones 21 (4), pp. 363-386.

Mitchell, K (2003). Educating the national citizen in neoliberal times: from the multicultural self to the strategic cosmopolitan. Transactions of the Institute of British Geographers 28 (4), pp. 387-403.

Moore, K. and Measham, F. (2008). It's the most fun you can have for twenty quid: motivations, consequences and Meanings of British Ketamine use. Addiction Research and Theory. 16, pp. 231-244.

Nally, D. (2011). The biopolitics of food provisioning. Transactions of the Institute of British Geographers 36 (1), pp. 37-53.

Nayak, A. (2006). Displaced masculinities: chavs, youth and class in the post-industrial city. Sociology-The Journal of the British Sociological Association 40 (5), pp. 813-831.

Pini, M. (2001). Club cultures and female subjectivity: the move from home to house. New York: Palgrave.

Redhead, S., Wynne, D. and O'Connor, J. (1997). The clubcultures reader: readings in popular cultural studies. Malden, MA: Blackwell.

Redhead, S. (1993). Rave off: politics and deviance in contemporary youth culture. Avebury: Aldershot.

Riley, S. C. E., Griffin, C. and Morey, Y. (2010). The case for 'everyday politics': evaluating neo-tribal theory as a way to understand alternative forms of political participation, using electronic dance music culture as an example. Sociology - The Journal of the British Sociologial Association 44 (2), pp. 345-363.

Saldanha, A. (2005). Trance and visibility at dawn: racial dynamics in Goa's rave scene. Social \& Cultural Geography 6 (5), pp. 707-721.

Saldanha, A. (2007). Psychedelic white: Goa trance and the viscosity of race. Minneapolis: University of Minnesota Press.

Scott, A. J. (2001). Capitalism, cities, and the production of symbolic forms. Transactions of the Institute of British Geographers 26 (1), pp. 11-23.

Talbot, D and Böse, M. (2007). Racism, criminalization and the development of night-time economies: two case studies in London and Manchester. Ethnic and racial studies 30(1), pp. 95-118.

Thornton, Sarah. (1996). Club cultures: music, media, and subcultural capital. Hanover: Wesleyan University Press.

Yarwood, R. and Charlton, C. (2009). 'Country life'? Rurality, folk music and 'show of hands'. Journal of Rural Studies 25 (2), pp. 194-206.

Zukin, S. (1990). Socio-spatial prototypes of a new organization of consumption: the role of real cultural capital. Sociology 24 (1), pp. 37-56.

Zukin, S. (1995). The cultures of cities. Oxford, UK: Blackwell.

\section{Further Reading}

Belle-Fortune, B. (1999). All crew muss big up: journeys through jungle drum \& bass culture. Basildon, UK: Remix.

Brewster, B. and Broughton, F. (1999). Last night a DJ saved my life. New York: Grove Press.

Reynolds, Simon. (1998). Generation ecstasy: into the world of techno and rave culture. Boston: Little, Brown and Company.

Smith, S.J (1997). Beyond geography's visible worlds. Progress in Human Geography 21 (4), pp. 502-529.

See also Dancecult: Journal of Electronic Dance Music Culture. [Online]. Retrieved on 19 July 2012 from: http:// dj.dancecult.net/ 